\title{
Experimental Reduction of Condenser Exit Temperature in VCR System with Condenser Jacket
}

\author{
${ }^{1}$ Dr.P.Anusha, ${ }^{2}$ Dr.M.Naga Swapna Sri, ${ }^{3}$ V.Sravani \\ 1,2,3 Assistant Professor, Department of Mechanical Engineering, \\ P V P Siddhartha Institute of Technology, \\ Kanuru, Vijayawada, Andhra Pradesh, India. \\ lanoosha.peyyala@gmail.com,
}

\begin{abstract}
The Air Conditioner's condenser chamber releases hot air into the environment which leads to increase in temperature which has a great impact on the environment. The exhaust air produced in the air conditioner was hot air, which led to an increase in global warming and a decrease in the ozone layer. The role of the Condenser jacket is to cool down the hot air that released from the condensers outlet unit. The mud glass and dry grass inserted in the aluminium mesh which absorbs the hot air with the help of water. So the hot air turns to cold and leads to a reduction in global warming due to waste heat. We aim to develop a condenser jacket that will be fitted to the air conditioner condenser resulting in a reduction in the air temperature generated from the condenser after the refrigeration process. The water coming from the air conditioner is made to flow through mud glass and dry grasses which are inserted in aluminium casing. So that the mud glass and dry grass became wet. Hot air passing through wet mud glass and grass gets cold in turn lowers the temperature of the exhaust air. The temperature of air released from condenser should be lowered by this component which would be installed infront of the condenser. The Change in temperature of the air is observed to be around $4^{\circ}-5^{\circ} \mathrm{C}$ which is dependent on the atmospheric weather conditions. So the temperature of the air from the condenser jacket outlet decreases which in turn contributes to lowering global warming to some extent.
\end{abstract}

KEYWORDS: Condenser Jacket, Exit Air Temperature, Global Warming, AC, Clay Pot, Dry Grass.

\section{INTRODUCTION:}

An air conditioner is an interior device that removes heat from a space or a confined area and moves it to an outdoor place to cool it down. A refrigerant is a substance that is treated in such a way that the cold refrigerant absorbs heat from a heated room from the evaporator by chilling the closed region.Evaporative cooling is a heat and mass transfer method that uses water evaporation to cool the air, transferring a huge quantity of heat from the air to the water and lowering the air temperature as a result. The three types of evaporative coolers are Direct coolers, Indirect coolers and Combined coolers.

Evaporative cooling, its potential, and diverse trends in evaporative cooling are investigated in

Bhushan D et al.[1] study, which is environmentally benign because it uses only natural energy as

latent heat of water. Evaporative cooling's efficiency and effectiveness are determined by the 
surrounding environmental conditions, and the faster the evaporation rate, the greater the cooling impact.

The work by Bogdan porumb et al.[2] presents current understanding on indirect evaporative cooling. This cooling technique has a bright future ahead of it because of its low energy consumption and great efficiency across a wide range of applications. Lower-temperature air can be created via dew-point evaporative coolers, according to Hongxing Yang et al[3]. Innovative wicks made of various materials improve surface wettability while also promoting evaporation. Indirect Evaporating Cooling is predicted to contribute more to reducing the energy consumption of air conditioning in buildings as a result of recent breakthroughs and foreseeable future chances to address these issues.According to Qinghan Bian et al [4, a large quantity of residual or waste heat from human activities has been poured into the climate system, but it has not been taken seriously in the context of global warming or climate change, which must be addressed.

Work by Sujatha Abaranji et al [5] combines a direct evaporative cooling system with solarassisted vermicompost drying to create a clean and sustainable indoor environment. This method could open the path for environmentally friendly year-round thermal management of building cooling applications.

The experimental work by R.Ramkumar et al[6] aims to explore the performance of an indirect evaporator cooler in hot and humid environments. In the cooler, an innovative method is used by placing clay pots in various positions and orientations

\section{CONCLUSION BY DOING LITERATURE REVIEW:}

- There is a scope to design condenser jacket to reduce the global warming.

- The main objective of condenser jacket is to contribute in reduction of the global warming caused due to the air produced from the condenser outlet of the air conditioners.

- The device aims to be more productive by using the water produces from the air conditioner as a drain outlet.

\section{EXPERIMENTATION:}

\section{FABRICATION DETAILS}

The Condenser jacket/jet has three major components:

Aluminium casing.

Aluminium mesh.

Mud glass.

Dry grass.

\subsection{Aluminium casing:}

Aluminium casing is to hold the aluminium mesh the aluminium casing is acts as the frame in condenser jacket which holds the aluminium mesh and also it is easy to fix 
the condenser jacket to the outdoor unit without this aluminium casing we cannot fix the condenser jacket to the outdoor unit. The dimensions of the aluminium casing are length:- $83 \mathrm{~cm}$ with height:- $62.7 \mathrm{~cm}$ and the thickness of $2.5 \mathrm{~cm}$.the design of the aluminium casing is done by using solid works software the design of aluminium casing with different views is given below

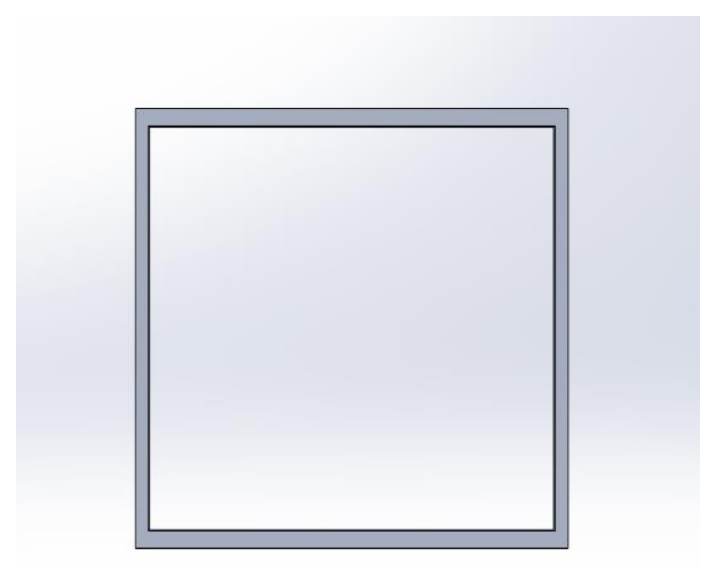

Figure 1: Front view of aluminium casing

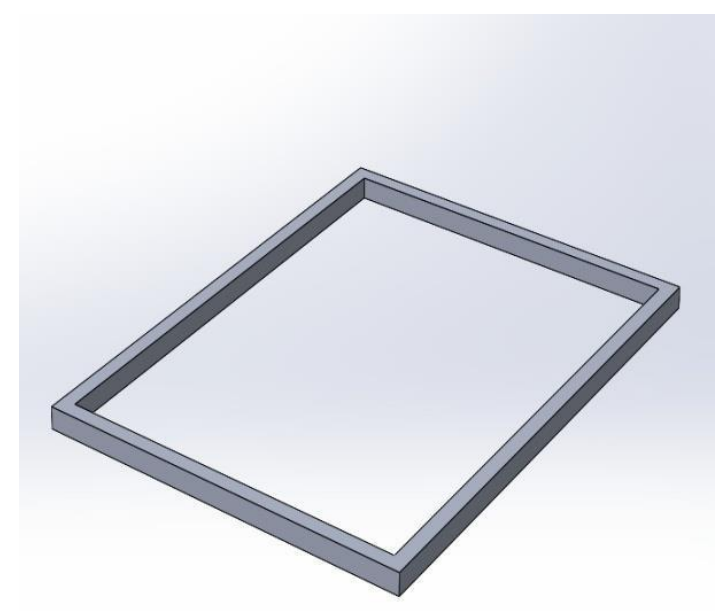

Figure 2: Side view of aluminium casing

We like to use aluminium over copper to seal metal because the cost of copper is higher than aluminium but the sheer cost of the device is increasing. So, we decided to use aluminium.

\subsection{Aluminium mesh:}


Aluminium Mesh is the second important component in the condenser jacket aluminium mesh is the component which holds the clay glass. The aluminium mesh is designed in such a way that the clay glasses are placed in the mesh without any obstruction and tight. the mesh consists of rhombus shaped hollows in which the clay glasses are placed. the dimensions of the rhombus shaped hollows are Diagonal:- $8.5 \mathrm{~cm}$ and the length of each side is $6 \mathrm{~cm}$.and the dimensions of the whole aluminium mesh are length:- $80.5 \mathrm{~cm}$ and the height:- $60.2 \mathrm{~cm}$.the design of the aluminium mesh is done by using solid works software the design of aluminium mesh with different views is given below

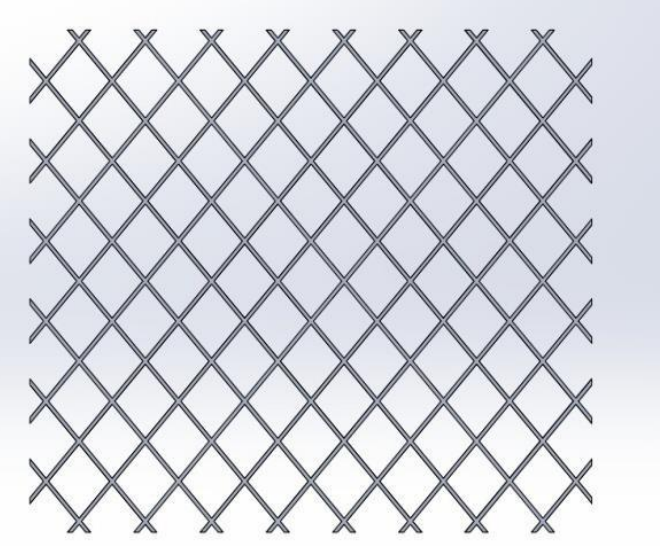

Figure 3: Front view of aluminium mesh

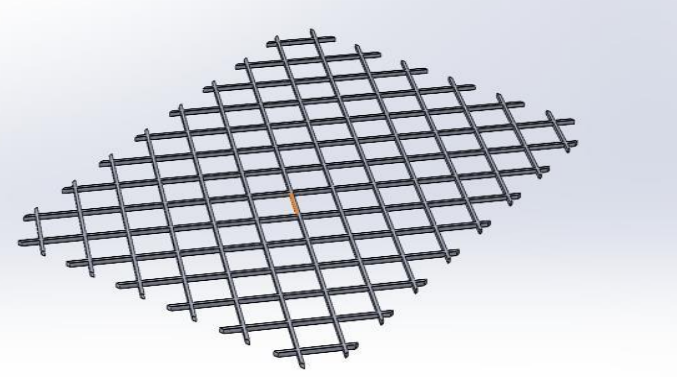


Figure 4: Side view of aluminium mesh

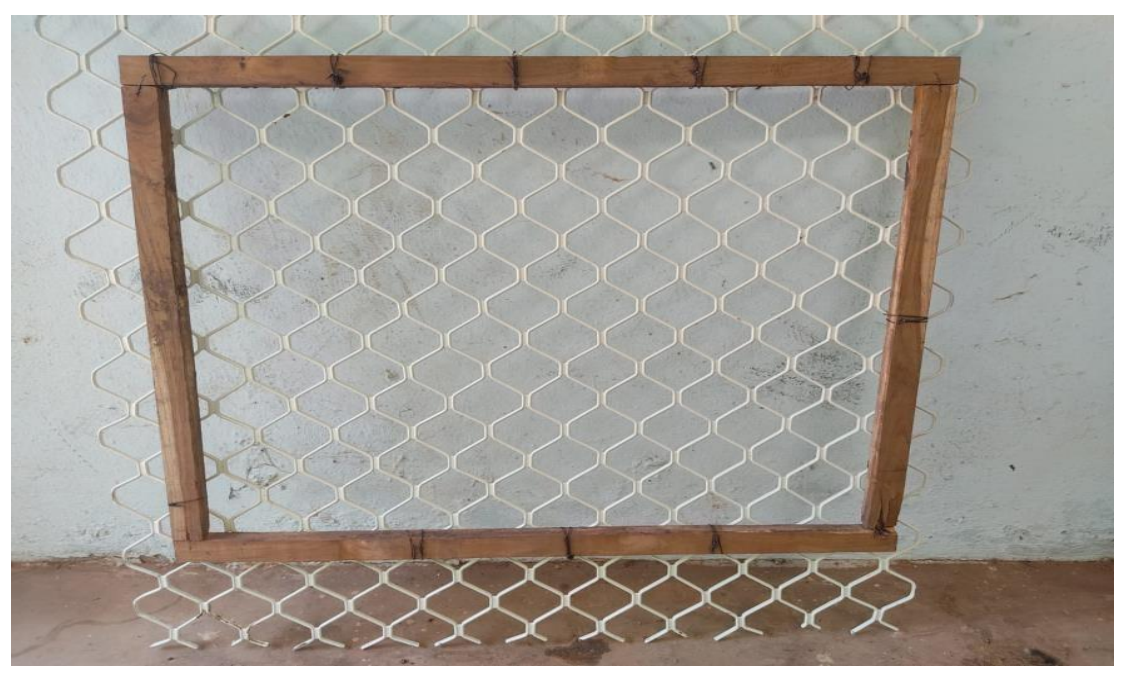

Figure 5: Aluminium mesh with wooden fram

The Aluminium mesh, initially we took $3 * 3$ sq feet of aluminium mesh. But later ,we diminished it size to our actually requirement .As shown in the figure 5 .The wooden frame is the required dimension for aluminium mesh. So we use this wooden frame as prototype to get the required size of aluminium mesh.

\subsection{Mud glass:}

Mud glass is the most important component in condenser jacket, why because the difference of temperature is takes place mainly based on this component. The composition of the mud glass is same as the composition of the normal clay.

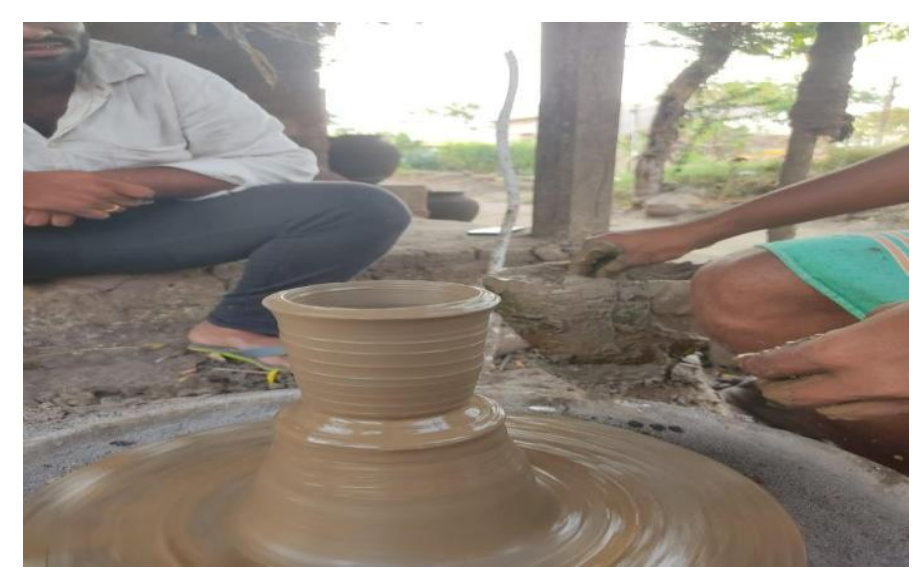

Figure6: Fabrication of glass 


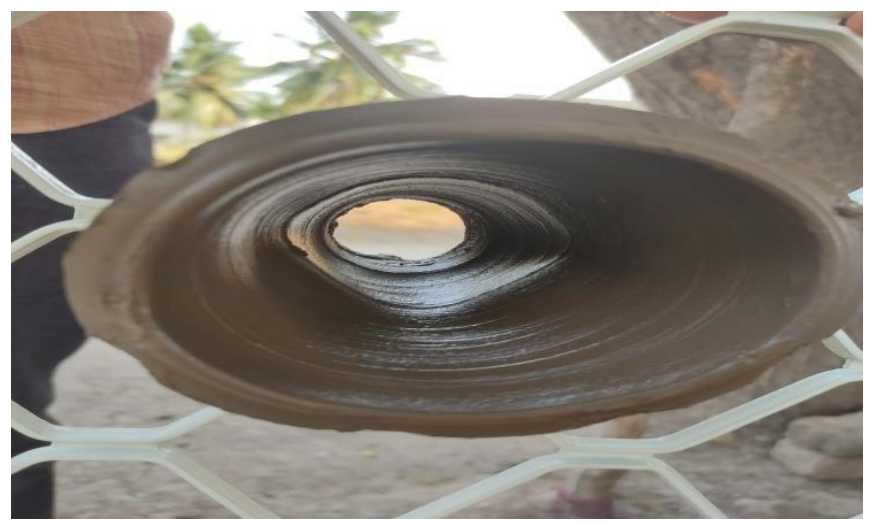

(a)

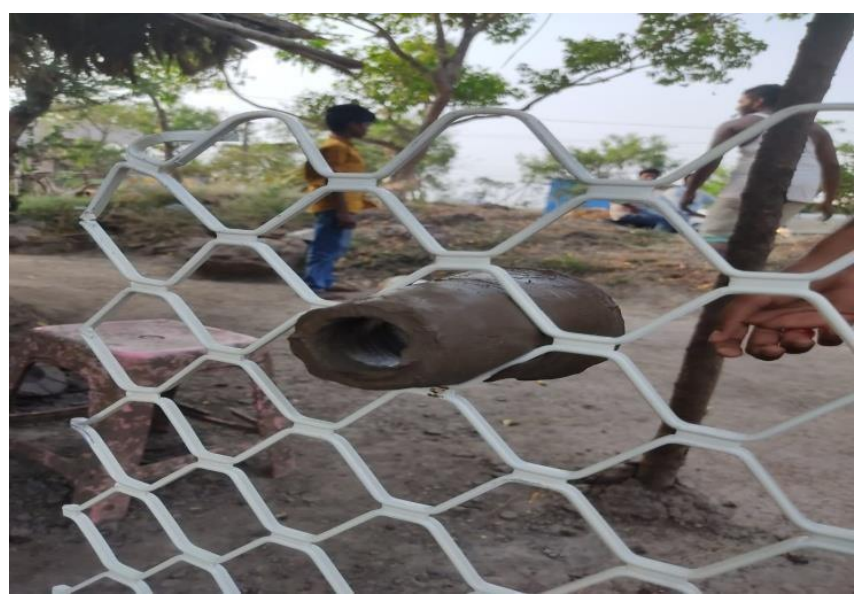

(b)

Figure 7 :(a),(b) Represents represents fabricated glass placed

in aluminium mesh

\subsection{Dry grass or Aspen wood wool:}

The Aspen wood wool is made up of wood shavings and synthetic fiber. They look alike almost grass. The most important property of Aspen wood wool is they are much cheaper, and are available at a very reasonable price. This aspen wood wool is optional to be used because it helps the mud tile to hold the moisture for a little bit more time which helps in increasing the efficiency of the condenser jacket. 


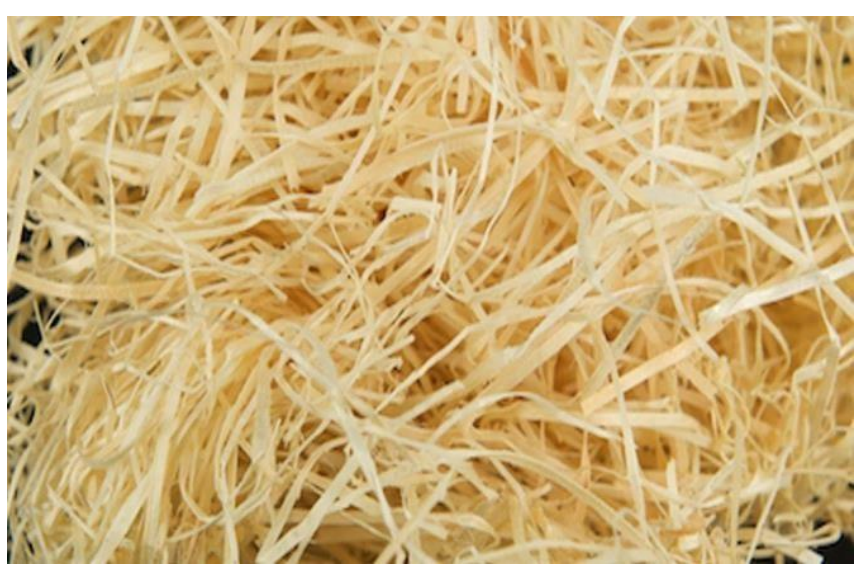

Figure 8: aspen wood wool

\section{CONSTRUCTION}

The main important component in the condenser jacket is as mentioned above it is clay glass. The clay glass is fixed on the aluminium mesh in those rhombus shaped hollows the clay glasses are kept in those hollows in a pattern one after another alternatively leaving spaces in between. After completing the arrangement of clay glass in aluminium mesh. The next immediate work is to incorporate the dry grass in between the left spaces and around the clay glasses. Then this total arrangement aluminium mesh is placed in the aluminium casing and after the entire setup is fixed to outdoor unit of the air conditioner. The prototype of the condenser jacket is given below.

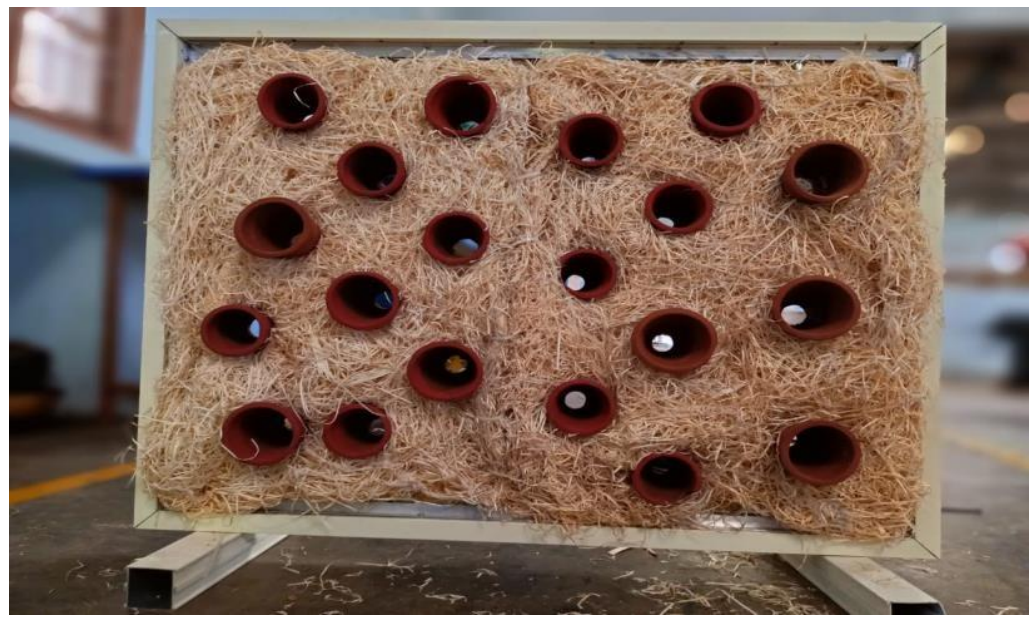

Figure9: Condenser jacket

\section{Working of Condenser jacket:}

The condenser jacket works under the basic principle of evaporative cooling,when the condenser jacket is attached to the outdoor unit we make sure that the outlet 
water of the condenser unit is flowed on the condenser jacket so that the clay glass and dry grass will become wet so that when the outdoor unit's hot air flows out and it goes through the condenser jacket due to this wet clay glass the hot air converts into cool air.that is how the condenser jacket works.

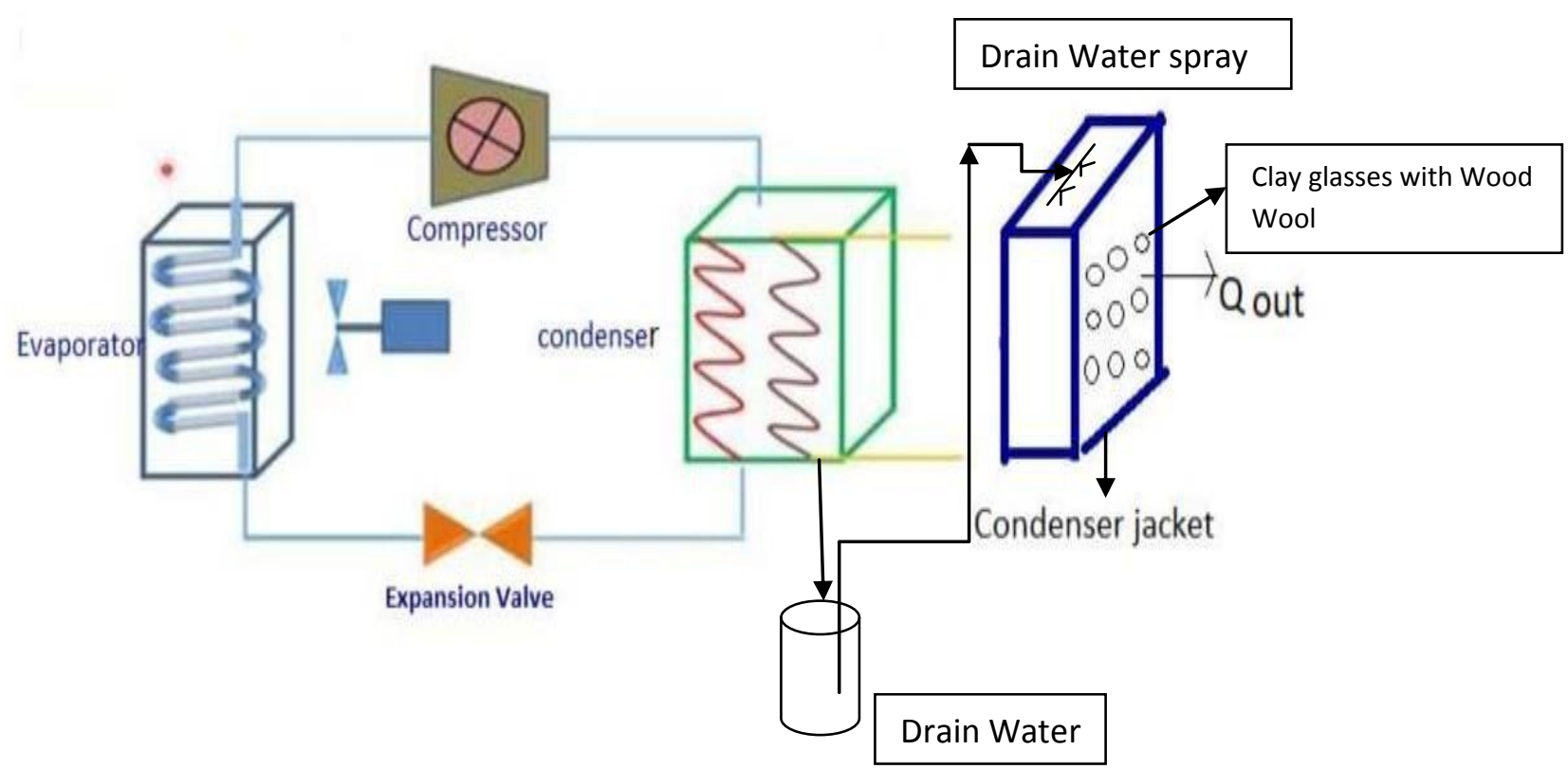

Figure 10: Basic VCR system with condenser jacket

The above Figure10 gives the detailing of the VCR system after installing the Condenser Jacket in front of the Condenser. So that the hot air released from the condenser will not directly released to atmosphere, Instead The hot air passes through the condenser jacket which will turn to cool the air may helps in decreasing the global warming.

\section{EXPERIMENTATION}

We took the readings of the condenser outlet temperature and condenser jacket out let temperature also the atmosphere temperature using digital thermometer.

After installing the device to the air conditioner we have noted down the temperature of the outlet air using a digital thermometer. 


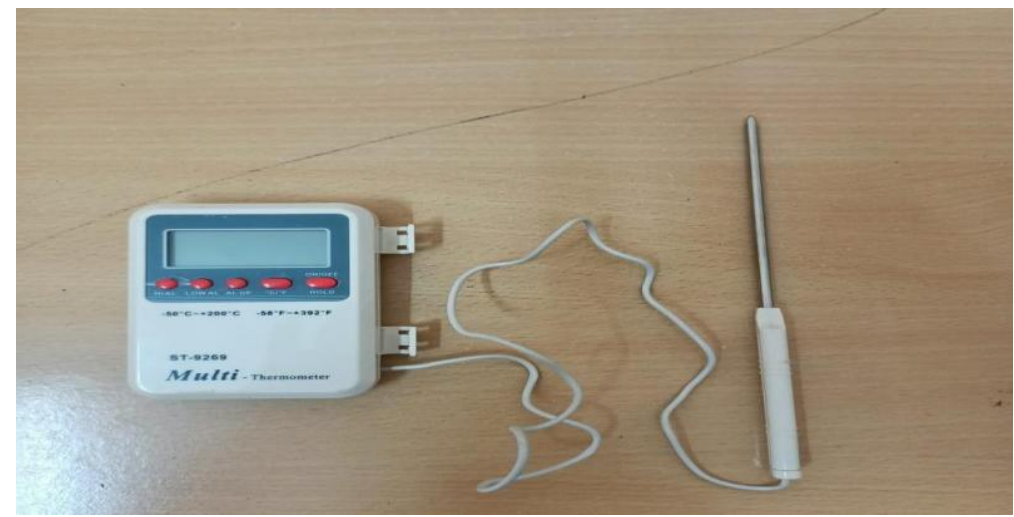

Figure 11: Digital thermometer

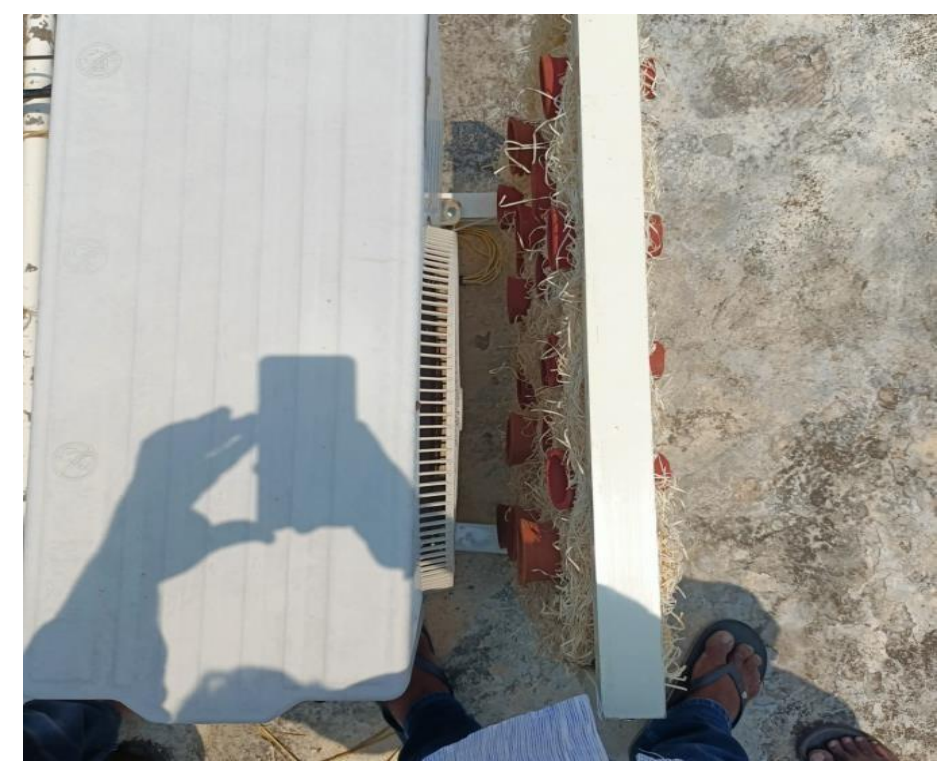

(a) 


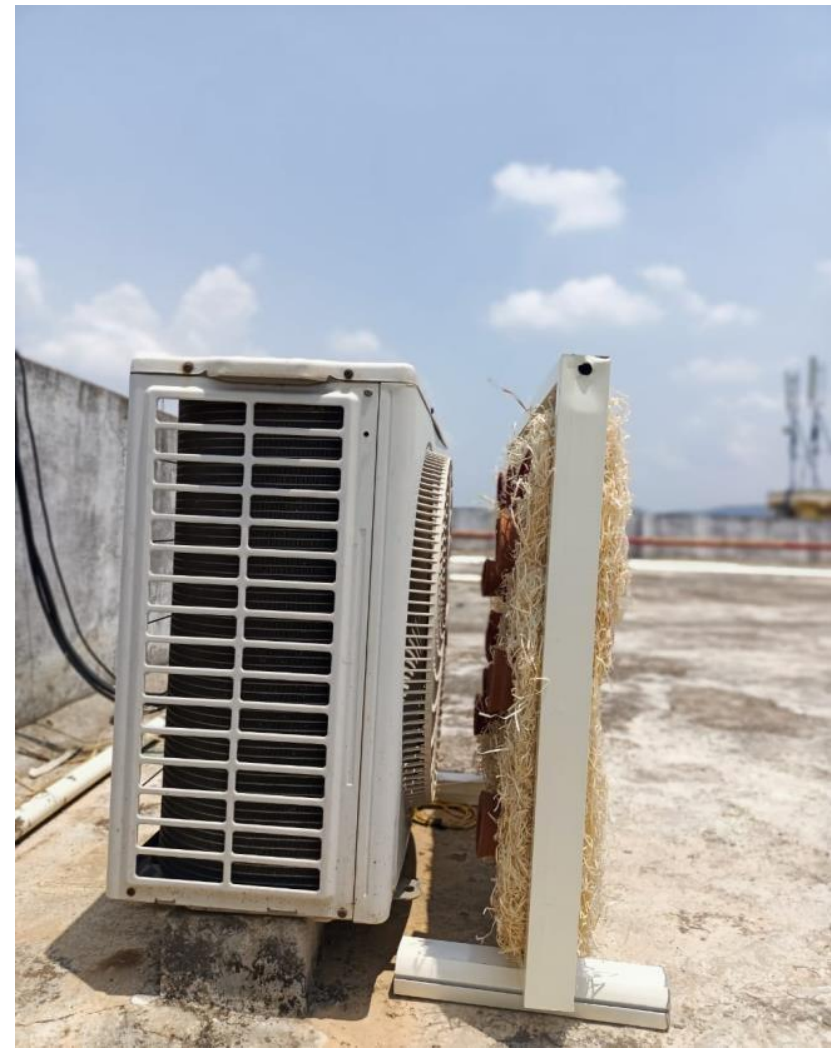

(b)

Figure12: (a),(b) Condenser jacket is placed just behind the condenser outlet, distance between condenser outlet and condenser jacket is around $15 \mathrm{~cm}$

\section{RESULTS AND DISCUSSIONS}

\begin{tabular}{|c|c|c|c|c|}
\hline S.NO & TIME & $\begin{array}{l}\text { Atmosphere } \\
\text { temperature in } \\
\text { C }\end{array}$ & $\begin{array}{l}\text { Condenser } \\
\text { outlet } \\
\text { Temperature in C }\end{array}$ & $\begin{array}{c}\text { Condenser } \\
\text { Jacket outlet } \\
\text { Temperature in C }\end{array}$ \\
\hline 1 & $11 \mathrm{AM}$ & 31.3 & 41.7 & 36.9 \\
\hline 2 & $12 \mathrm{AM}$ & 33.2 & 43.1 & 38.9 \\
\hline 3 & $1 \mathrm{PM}$ & 35.8 & 44.2 & 39.8 \\
\hline 4 & 2PM & 36.6 & 44.6 & 40.3 \\
\hline 5 & $3 \mathrm{PM}$ & 35.2 & 44.1 & 39.8 \\
\hline 6 & $4 \mathrm{PM}$ & 34.1 & 43.2 & 38.6 \\
\hline
\end{tabular}

Table6: experiment readings 


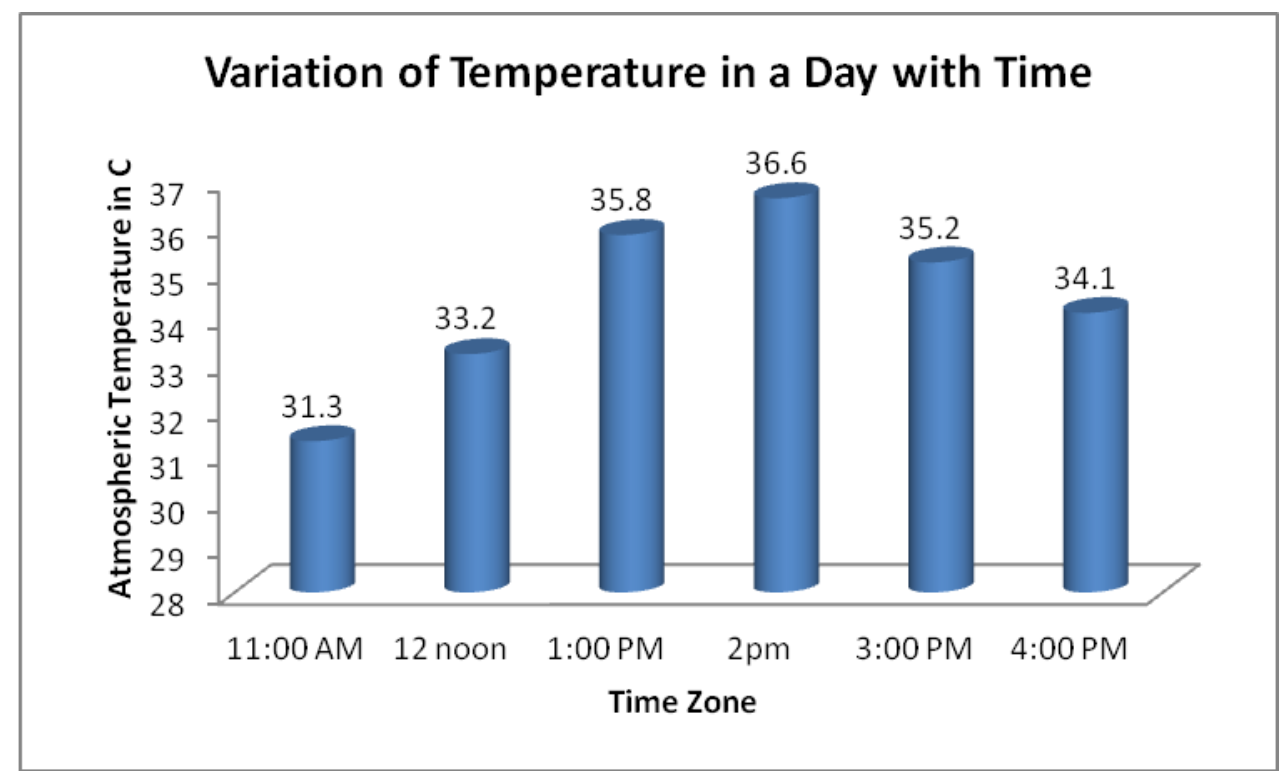

\section{Condenser Outlet Temperature Value}

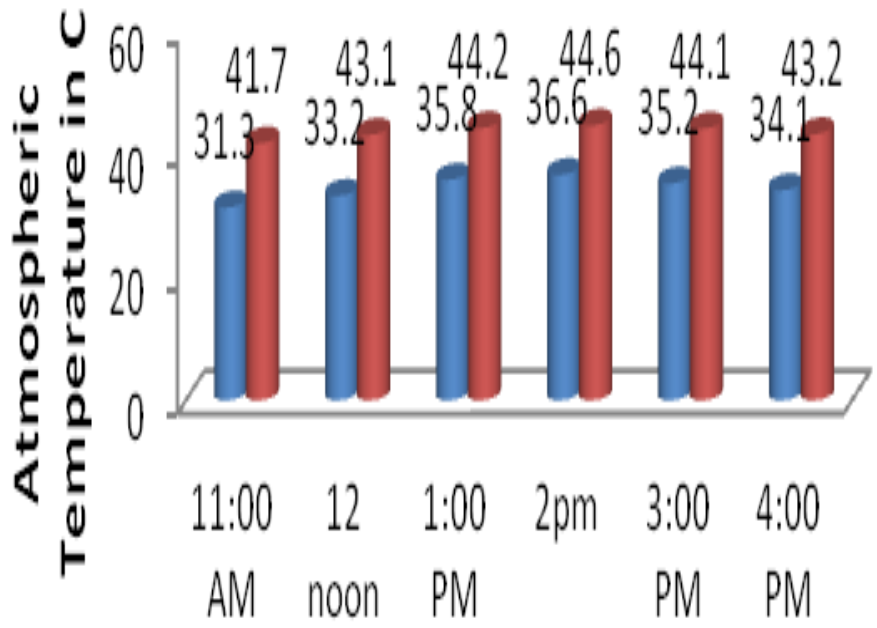

Atmospheric Temp in C

Condenser outlet temperature in C

Timezone 

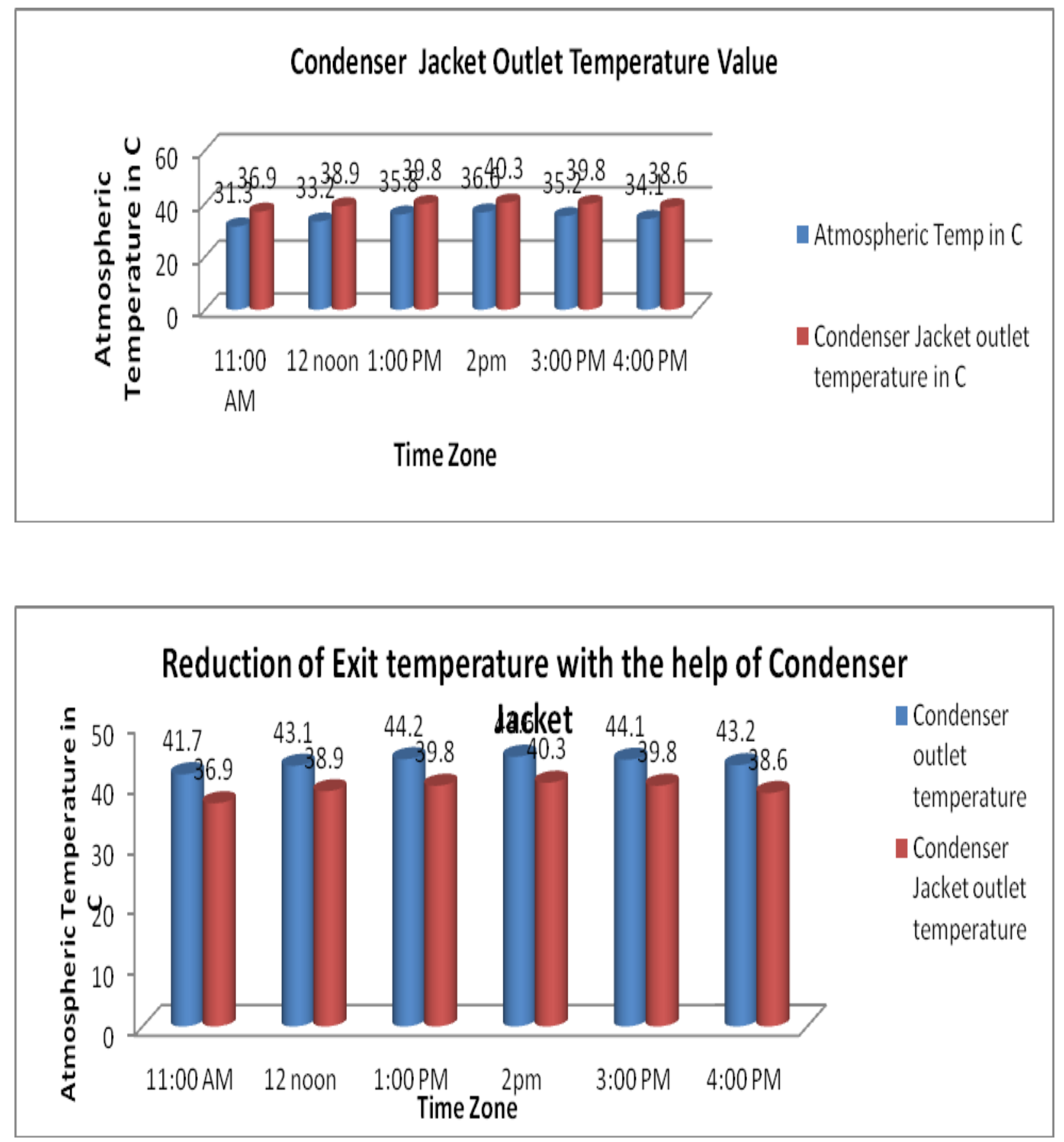

By observing the above graphs, we can understand that there is a difference in heat rejection values with Condenser Jacket \& without condenser jacket.

From the experimental reading values we can understand that the addition of Condenser Jacket is reducing the temperature of the air from the condenser outlet, in turn reducing the global warming. The temperature of the air released from the condenser was taken using the digital thermometer and noted down for further references. The difference between the condenser outlet temperature and the condenser jacket outlet temperature is around $4^{\circ}$ to $5^{\circ} \mathrm{C}$. The temperature of the air 
released from the condenser was taken using the digital thermometer and noted down for further references.

The air temperature blown out by the condenser was observed on the floor before and after installing the condenser jacket.

\section{CONCLUSION}

By the assembly of aluminium mesh, mud glass, dry grass, aluminium casing the condenser jacket is manufactured. The role of the condenser jacket is to cool down the hot air that comes out from the outlet of condenser unit. The mud glass and dry grass is inserted in the aluminium mesh which absorbs the hot air with the help of water. So the hot air turns to cold which in turn leads to a reduction of global warming due to waste heat. As a result, the temperature of the air leaving the condenser outlet drops, which in turn contributes to lowering global warming to some extent.

\section{FUTURE SCOPE:}

By using electricity we can circulate the drain water from the condenser jacket and other one is we can use any composite materials to increase heat transfer rate. Here we used clay or mud glass and dry grass (reason for using mud glass and dry grass is they are natural and cost effective).If needed we can use any composite materials that will increase the heat transfer rate.

\section{REFERENCES}

1. Bhushan D. Chaudhari, Tushar R. Sonawane, Shubham M. Patil, Prof. Anil Dube , "A Review on Evaporative Cooling Technology”,International Journal of Resarch in Advent Trchnology.

2. Bogdan Porumb, Paula Ungureşan, Lucian Fechete Tutunaru, Alexandru Şerban,Mugur Bălan," A review of indirect evaporative cooling technology", Sustainable Solutions for Energy and Environment, EENVIRO - YRC, Bucharest, Romania.

3. Hongxing Yang, “WenchaoShi,YiChen,YunranMin," Research development of indirect evaporative cooling technology", Renewable and Sustainable Energy Reviews. 
4. Qinghan Bian, "Waste heat: the dominating root causeof current global warming", Bian Environ Syst Res 9:8 https://doi.org/10.1186/s40068-020-00169-2. 5. Sujatha Abaranji, Karthik Panchabikesan, and Velraj Ramalingam, "Experimental Investigation of a Direct Evaporative Cooling System for YearRound Thermal with Solar-Assisted Dryer", https://doi.org/10.1155/2020/6698904. 6.R.Ramkumar and A.Ragupathy, " Performance evaluation of indirect evaporative cooler using clay pot”, https://doi.org/10.1063/1.4946132. 